\title{
A REGIÃO METROPOLITANA DE NATAL-RN: UM PROCESSO AINDA EM CURSO
}

\author{
J. M. VASCONCELOS FILHO e G. G. NASCIMENTO*
}

Instituto Federal de Educação, Ciência e Tecnologia do Rio Grande do Norte - Campus Natal Central gerson.nascimento@ifrn.edu.br*

Artigo submetido em dezembro/2014 e aceito em dezembro/2014

DOI: 10.15628/geoconexoes.2015.2616

\section{RESUMO}

A institucionalização das Regiões Metropolitanas (RMs) brasileiras obedeceu a duas fases. A primeira, nos anos de 1970, como parte da política de desenvolvimento urbano, relacionada à expansão da produção industrial e à consolidação das metrópoles como lócus desse processo. Reguladas por legislação federal, foram criadas, a princípio, nove RMs. A segunda teve início com a Constituição Federal de 1988, que facultou aos estados federados a competência de institucionalização de suas unidades regionais. Nesse sentido, chegava ao fim um modelo que criou regiões sobre as quais os estados federados não tinham autonomia e se abria a possibilidade de inserção de RMs em processos estaduais de planejamento regional. $\mathrm{Na}$ atualidade, observamos que grande parte dessas áreas metropolitanas no Brasil não tem um perfil bem definido, nem caracterização própria e, muito menos, identidade metropolitana. Desse modo, vazios urbanos consideráveis são identificados entre municípios de RMs bem como ausência de problemas comuns, gerando sérios problemas socioespaciais nessas áreas. No caso da RMN (Região Metropolitana de Natal), observamos que esta a cada dia está se consolidando enquanto processo em curso, guardando algumas especificidades nesse processo recente de formação.

PALAVRAS-CHAVE: Região Metropolitana de Natal; Desenvolvimento Urbano; Problemas Socioespaciais.

\section{THE METROPOLITAN REGION OF NATAL-RN: A PROCESS STILL ONGOING}

\begin{abstract}
The institutionalization of the Metropolitan Regions Brazilian (RMs) obeyed to two phases. The first one, in the years of 1970, like part of the politics of urbane development, made a list to the expansion of the industrial production and to the consolidation of the metropolises like lócus of this process. Regulated by federal legislation, nine RMs was raised, to beginning. The second one had beginning with the Federal Constitution of 1988, which it allowed to the states federated into the competence of institutionalization of his regional unities. In this sense, there was reaching the end a model that created regions on which the federate
\end{abstract}

states had no autonomy and there was opening the possibility of insertion of RMs in state processes of regional projection. In the present, we notice which great part of these metropolitan areas in Brazil has not a quite definite profile, not even own and, characterization much less, metropolitan identity. In this way, empty urbane considerable they are identified between local authorities of RMs as well as absence of common problems, producing serious socioespaciais problems in these areas. About the Metropolitan Region form Natal, some charters so observed because it's a recent process.

KEYWORDS: Natal Metropolitan Region; Urbane Development; Socioespaciais Problems. 


\section{AS RMS BRASILEIRAS: CONSIDERAÇÕES IMPORTANTES}

A institucionalização das Regiões Metropolitanas (RMs) brasileiras obedeceu a duas fases. A primeira, nos anos de 1970, como parte da política de desenvolvimento urbano, relacionada à expansão da produção industrial e à consolidação das metrópoles como lócus desse processo. Reguladas por legislação federal, foram criadas, a princípio, nove RMs. A segunda teve início com a Constituição Federal de 1988, que facultou aos estados federados a competência de institucionalização de suas unidades regionais. Nesse sentido, chegava ao fim um modelo que criou regiões sobre as quais os estados federados não tinham autonomia e se abria a possibilidade de inserção de RMs em processos estaduais de planejamento regional. Sobre o processo de criação das primeiras RMs no Brasil, Gouvêa (2005) nos mostra que

Historicamente, o I Plano Nacional de Desenvolvimento (I PND), implementado durante o governo Médici (1969-74), foi o primeiro a apresentar os termos "espacial, regional e urbano", integrando o rol das diretrizes econômicas, no bojo das estratégias formuladas para o desenvolvimento do país. Entre outras medidas, o plano recomendava a criação de regiões metropolitanas e reforçava ainda mais o modelo centralizador e verticalizador que vinha orientando as ações governamentais desde o golpe militar de 1964 (GOUVÊA, p. 90, 2005).

Clementino e Andrade (2007), sobre essa questão nos mostram que

O novo arranjo federativo implantado com a Constituição democrática de 1988, ao garantir aos municípios a condição de unidade federativa, como os estados e a união provocaram o desmonte de grande parte dos arranjos institucionais de base centralizada. Essa mudança transformou os municípios em unidades políticas estratégicas para a formação e implementação de políticas públicas, definindo um novo patamar para os mesmos, tanto do ponto de vista financeiro como políticoadministrativo (ANDRADE; CLEMENTINO, 2007 p. 242).

Naquela época, a questão metropolitana veio reforçar a idéia de que a importância econômica das áreas urbanas transcendia os interesses municipais e de que o governo federal deveria assumir parte das responsabilidades da gestão urbana. Considerava-se, então, que o lócus da produção havia se deslocado para os grandes centros urbanos, na medida em que as cidades passaram a ser vistas não só como espaço de vivência, mas também como importantíssimas unidades de produção. Era preciso, pois, que se cuidasse de sua administração, em busca de eficiência enquanto espaço produtivo, uma vez que o processo de urbanização era irreversível. Conforme opina Cintra (1978, p. 179)

[...] o que acontece na esfera urbana fica mais importante para o país como um todo, transcendendo, portanto, a restrita definição pré-urbana de interesse exclusiva ou predominantemente local. Assim, era bastante natural que a rede formada pelos grandes centros urbanos passasse a ser entendida como matéria de interesse do governo central.

Para Vasconcelos e Câmara (2006), as regiões metropolitanas foram 
Concebidas como parte integrante da política nacional de desenvolvimento urbano, essas regiões deveriam se constituir como unidades do planejamento integrado, do desenvolvimento econômico e social, organizadas sob um arcabouço padrão com a missão de realizar serviços comuns de interesse metropolitano, sobretudo nas áreas de saneamento ambiental, uso do solo, transportes e sistema viário e aproveitamento de recursos hídricos (VASCONCELOS; CÂMARA, 2006, p. 10).

Em geral, os processos de urbanização acelerada e de metropolização no Brasil ocorrem simultaneamente à concentração de atividades industriais, por força das oportunidades de mercado e das óbvias vantagens oferecidas pela existência de significativos contingentes humanos migrando para os grandes centros. O crescimento das metrópoles brasileiras resultou, fundamentalmente, de um processo de expansão do núcleo central e de absorção gradativa de espaços periféricos. As relações núcleo-periféricas se intensificaram e se orientou, durante certo tempo, segundo uma estrutura composta de anéis sucessivos, apresentando ciclos de crescimento, de deteriorização e de mudanças nos padrões de uso do solo.

Todavia, devemos ressaltar que, além de regiões metropolitanas, a Constituição de 1988, em seu artigo 25 , parágrafo 30 , admitiu outras categorias de organização regional, como as aglomerações urbanas e as microrregiões. Adequando os objetivos da etapa anterior, as unidades criadas deveriam integrar a organização, o planejamento bem como a execução de funções públicas de interesse comum. No caso de aglomerações que envolvessem municípios de mais de uma unidade federativa, a Constituição Federal $^{1}$ previu a institucionalização das Regiões Integradas de Desenvolvimento (RIDEs), mantendo a competência de sua institucionalização na União.

\section{A NOVA CONSTITUIÇÃO BRASILEIRA E AS RMS}

A possibilidade aberta pela Constituição desencadeou um contínuo ciclo de institucionalização de novas unidades regionais, quase sempre classificadas como metropolitanas. $\mathrm{Na}$ maioria dos casos, essas unidades abrangeram áreas que se formaram ou se consolidaram como espaços de crescimentos e ocupação contínuos nas últimas décadas, polarizados por capitais de estados ou centros regionais. Todavia, observamos que algumas legislações estaduais incorporam ao conjunto metropolitano municípios situados nos limites da unidade institucionalizada sob a denominação de áreas de expansão metropolitanas ${ }^{2}$.

Além dos inúmeros projetos de lei em tramitação, o Brasil encerrou o ano de 2003 com 26 RMs oficialmente instituídas, e duas RIDs no entorno de capitais. Essas unidades compõem um conjunto díspar, dada a existência de critérios legais e de normas específicas que instruam demarcações para as categorias espaciais a serem instituídas pelos estados, dificultando sua comparabilidade. Embora apresentem, em parte, um padrão de ocupação que se particulariza por transcender limite político-administrativos municipais, descrevendo manchas contínuas assentadas sobre município limítrofe, à delimitação do perímetro nem sempre expressa contornos conexos a esse aglomerado, incluindo municípios alheios ou com mínima relação à sua dinâmica.

\footnotetext{
${ }^{1}$ Conforme artigo 21, inciso IX; artigo 43; artigo 48, inciso IV da Constituição Federal do Brasil.

2 É o caso, por exemplo, de Santa Catarina (Colar Metropolitano), em Minas Gerais e Goiás (Região de Desenvolvimento Integrado).
} 
As palavras de Andrade e Clementino (2007), sobre os critérios para se criarem as regiões metropolitanas no Brasil nos mostram que

\begin{abstract}
Naquele momento, os critérios de definição das áreas metropolitanas, foram critérios essencialmente técnicos, resultantes de estudos realizados pelo IBGE e alguns ministérios, e estavam respaldados na especificidade da dinâmica de suas economias e na gravidade de seus problemas sociais. A isso tudo se somava o fato de que, nessas áreas, estava concentrada a maior parte do voto de oposição aos candidatos governistas, nas eleições proporcionais. Dessa forma, eram espaços problemáticos do ponto de vista social e político (ANDRADE; CLEMENTINO, 2007 p. 241).
\end{abstract}

Outro fato a ser considerado é que estes não refletem também aderência à base conceitual das categorias dispostas na lei, que distinguiria a unidade metropolitana das demais categorias disponíveis para institucionalização. A clareza com relação a esses aspectos é fundamental na definição de políticas públicas urbanas, seja pela adequação do conteúdo, seja pela definição de incidência, uma vez que a vertiginosa expansão das áreas metropolitanas brasileiras conferiu a problemas urbanos, como, demandas crescentes de transporte público, uma dimensão que os Estados Unidos e os países europeus, de mais antiga e ordenada industrialização e urbanização, jamais conheceram.

A formação de grandes cidades num curso espaço de tempo, as quais igualam ou mesmo superam em população as principais cidades dos países desenvolvidos, passou a exigir uma contínua aplicação de quantias significativas na implantação de novas estruturas de transportes e na ampliação das existentes. Porém, de modo geral, os recursos disponíveis, disputados também por outras políticas sociais estratégicas, nunca atenderam, nem de longe, às demandas de transporte geradas pelo crescimento intenso da metrópole do país.

Desse modo, o fenômeno da metropolização, no Brasil, caracterizou-se basicamente por um intenso ritmo de crescimento urbano em torno das principais capitais estaduais. Assim, em 1973, através da Lei Complementar Federal n‥ 14 foram criadas as oito primeiras RMs brasileiras: Belém, com 2 municípios; Belo Horizonte, com 14; Curitiba, com 14; Fortaleza com 5; Porto Alegre, com 14; Recife, com 9; Salvador com 8; São Paulo com 37 municípios. No ano seguinte, após a fusão dos estados do Rio de Janeiro e da Guanabara, surgiu, também através de lei complementar, a Região Metropolitana do Rio de Janeiro , composta por 14 municípios. Assim, a criação das primeiras RMs foi possível tendo em vista a introdução de um dispositivo no texto constitucional de 1967, advindo de uma emenda de Eurico Rezende, então senador. Tal dispositivo autorizava a União a criar RMs mediante lei complementar ${ }^{3}$. O quadro 1 mostra a evolução, ao longo do período de 1940-2000, das nove principais metrópoles e regiões metropolitanas mais antigas do país.

Quadro 01: Metrópoles e Regiões Metropolitanas brasileiras*/ Evolução Populacional (1940-2000).

\begin{tabular}{|c|c|c|c|c|c|c|c|}
\hline $\begin{array}{c}\text { Região } \\
\text { Metropolitana }\end{array}$ & $\mathbf{1 9 4 0}$ & $\mathbf{1 9 5 0}$ & $\mathbf{1 9 6 0}$ & $\mathbf{1 9 7 0}$ & $\mathbf{1 9 8 0}$ & $\mathbf{1 9 9 1}$ & $\mathbf{2 0 0 0}$ \\
\hline Belém & $\mathbf{2 0 6}$ & $\mathbf{2 5 5}$ & $\mathbf{3 9 9}$ & 633 & $\mathbf{9 9 9}$ & 1.333 & 1.796 \\
\hline Belo Horizonte & 211 & 353 & 683 & 1.235 & 2.540 & 3.436 & 4.358 \\
\hline Curitiba & 142 & 181 & 357 & 484 & 1.441 & 2.001 & 2.727 \\
\hline Fortaleza & 180 & 270 & 507 & 520 & 1.580 & 2.269 & 2.985 \\
\hline
\end{tabular}

\footnotetext{
${ }^{3}$ Sobre esta questão ver: Constituição do Brasil, 1967, art. 157, inciso 10.
} 


\begin{tabular}{|c|c|c|c|c|c|c|c|}
\hline Porto Alegre & 266 & 324 & 635 & 886 & 2.231 & 3.027 & 3.719 \\
\hline Recife & 348 & 525 & 788 & 1.061 & 2.347 & 2.682 & 3.338 \\
\hline Rio de Janeiro & 1.764 & 2.378 & 4.862 & 6.719 & 9.014 & 9.815 & 10.894 \\
\hline Salvador & 290 & 417 & 650 & 1.007 & 1.767 & 2.497 & 3.022 \\
\hline São Paulo & 1.326 & 2.198 & 3.602 & 5.925 & 12.584 & 15.445 & 17.879 \\
\hline
\end{tabular}

Fonte: IBGE: $1940-2000$.

* Os dados relativos ao período 1940-1970, referem-se às populações dos municípios polarizados, em torno dos quais foram institucionalizadas, em 1973 e 1974, as primeiras regiões metropolitanas brasileiras. Os dados de 1980 em diante, apresentam, efetivamente, as populações metropolitanas, que cresceu devido, não só ao crescimento vegetativo e à migração, mas também a inclusão de novas municipalidades no conjunto inicialmente formado.

Como já mencionado, a Constituição de 1988 transferiu da União para os estados à responsabilidade de criar regiões metropolitanas ${ }^{4}$. Em 2000, o Brasil já possuía 22 RMs. Segundo o IBGE, elas reuniam, nesse período, 63,7 milhões de habitantes, ou seja, 37,5\% da população do país. Apenas as regiões metropolitanas de São Paulo, do Rio de Janeiro e de Belo Horizonte representavam juntas, quase $20 \%$ de toda a população brasileira (IBGE, 2000). Todavia, apesar de nas últimas décadas, ter-se verificado um ligeiro declínio na taxa de crescimento populacional dessas áreas, a participação da população das regiões metropolitanas no conjunto da população nacional continua elevada. O quadro 2 indica os percentuais de participação, na população do país, do contingente humano que vivia nas principais metrópoles e RMs no período de 1960-2000.

Quadro 2: Metrópoles e RMs brasileiras/ participação na população do país.*

\begin{tabular}{|c|c|c|c|}
\hline ANO & $\begin{array}{c}\text { POPULAÇÃO } \\
\text { TOTAL }\end{array}$ & $\begin{array}{c}\text { POPULAÇÃO } \\
\text { METROPOLITANA }\end{array}$ & $\begin{array}{c}\text { TAXA DE PARTICIPAÇÃO } \\
\text { (\%) }\end{array}$ \\
\hline 1960 & 70.967 & 12.483 & 17,6 \\
\hline 1970 & 93.139 & 18.470 & 19,8 \\
\hline 1980 & 119.003 & 34.503 & 29,0 \\
\hline 1991 & 146,826 & 42.505 & 29,0 \\
\hline 2000 & 169.873 & 63.735 & 37,5 \\
\hline
\end{tabular}

Fonte: IBGE, 1970-2000.

* Os dados relativos a 1960 e 1970, referem-se, apenas, às populações dos municípios pólos, que vieram a formar, em 1973 e 1974, as primeiras regiões metropolitanas brasileiras. Os dados referentes a 1980 e 1991, informam as populações das nove RMs mais antigas. A população do ano de 2000 inclui também as 13 RMs criadas entre 1995 e 2000.

Ainda no que se refere às RMs brasileiras, devemos destacar que, o crescimento populacional nos últimos anos tem-se mostrado intenso nas áreas metropolizadas do que propriamente nos municípios pólos. Em outras palavras, as capitais estaduais estão crescendo a taxas bem inferiores às registradas nos municípios vizinhos. Essa desaceleração deve-se, em parte, ao fato de as capitais já estarem densamente povoadas e porque ai o custo da terra é demasiadamente elevado para os migrantes oriundos de outras áreas urbanas ou mesmo das zonas rurais e, em parte, a real diminuição do crescimento vegetativo.

Em contrapartida, muitos dos municípios periféricos as sede dos governos estaduais, notadamente os mais pobres, continuam apresentando taxas de crescimento superiores a $4 \%$ ao ano. $O$ quadro 3 evidencia que as regiões metropolitanas que mais cresceram entre o período de

\footnotetext{
${ }^{4}$ Em seu artigo 25, a Constituição Federal de 1988 estabelece que os estados possam, mediante lei complementar, instituir regiões metropolitanas, aglomerados urbanos e microrregiões constituídas por agrupamentos de municípios limítrofes, a fim de integrar a organização, o planejamento e a execução de funções públicas de interesse comum.
} 
1991 e 2000 foram as de Curitiba, Belém e Fortaleza, todas as taxas superiores a 3\%, enquanto as RMs do Rio de Janeiro e de São Paulo registraram os menores crescimento, abaixo de $2 \%$ ao ano (IBGE, 2000).

Quadro 3: Capitais estaduais e RMs/ taxas de crescimento populacional (1991-2000).

\begin{tabular}{|c|c|c|}
\hline REGIÃO METROPOLITANA & $\begin{array}{c}\text { TAXA DE CRESCIMENTO DA } \\
\text { CAPITAL (\%) }\end{array}$ & $\begin{array}{c}\text { TAXA DE CRESCIMENTO DA } \\
\text { REGIÃO METROPOLITANA }\end{array}$ \\
\hline Belém & 0,32 & 3,37 \\
\hline Belo Horizonte & 1,15 & 2,68 \\
\hline Curitiba & 2,11 & 3,50 \\
\hline Fortaleza & 2,15 & 3,09 \\
\hline Porto Alegre & 0,83 & 2,31 \\
\hline Recife & 1,02 & 2,51 \\
\hline Rio de Janeiro & 0,74 & 1,17 \\
\hline Salvador & 1,83 & 2,14 \\
\hline São Paulo & 0,88 & 1,64 \\
\hline
\end{tabular}

Fonte: IBGE, 1991-2000.

Nesse contexto, do ponto de vista político-administrativo das regiões metropolitanas brasileiras, muitas outras inovações foram apresentadas pela nova Constituição, levando a mudanças gradativas no plano institucional ao nível local, dentre elas podemos destacar: certo incentivo ao planejamento, através da prerrogativa da elaboração da Lei Orgânica, da obrigatoriedade do Plano Diretor para os municípios com mais de 20.000 habitantes e do Orçamento Plurianual de Investimentos (OPI), além da descentralização de alguns serviços públicos, tais como: saúde, assistência e educação, que transformou o município em lócus das ações do governo.

O problema mais visível de toda essa mudança é que, ao mesmo tempo em que se transfere ao município a responsabilidade das ações governamentais, faltam mecanismos para tornar isso possível, principalmente pela ausência de qualquer articulação entre os diferentes níveis de governo. De um lado, porque a burocracia federal resiste à perda de seu poder de distribuição de recursos, de outro, porque o poder municipal se recusa a assumir novas responsabilidades, pela insegurança em termos de recursos que possam garantir a realização de ações afetivas. Como lembra Almeida (1995), a

Mudança de tal magnitude não poderia ocorrer do dia para a noite, como consequência automática de novas normas constitucionais. Ela supõe um complexo processo de trânsito envolvendo a promulgação de legislação complementar aos dispositivos da Constituição, definindo regras e novos instrumentos para relocação, consolidação ou devolução de função entre instâncias de governo; a negociação de conflitos resultantes das mudanças propostas; a redefinição de objetivos e a reforma administrativa dos aparatos governamentais cujas atribuições se modificaram (ALMEIDA, 1995, p. 92).

Diante desse quadro, os municípios tendem a pensar os seus problemas de forma isolada, evitando ações cooperativas que, de imediato não podem garantir a solução dos problemas, aumentando a pressão social local. Instala-se, assim, um típico problema de ação coletiva e, sem ação coletiva e/ou cooperativa, não há solução para as regiões metropolitanas, uma vez que os problemas ultrapassam os limites territoriais municipais. Assim, a constituição de regiões 
metropolitanas passa a ser encarada como uma solução para problemas de natureza econômica do tipo: tarifa de transportes urbanos, telefonia, iluminação pública etc. Nesse sentido, é dado um tratamento genérico à questão, delegando aos estados a maioria das definições de suas atribuições, antes concentrada na União.

No caso das metrópoles, a questão é ainda mais grave uma vez que a descentralização e o aumento da autonomia municipal acabam evidenciando claramente a não legitimidade e representatividade dos organismos existentes de gestão metropolitana, contribuindo para esvaziálos ainda mais, quando não para extingui-los. Em temas essenciais como as políticas de investimento e gestão de infraestrutura, ou o desenvolvimento econômico, diante da ausência de um espaço político regional, as forças políticas locais acabam sendo sub-representadas em processos decisórios essenciais para o desenvolvimento local, centralizados na esfera estadual e federal.

Contudo, uma questão que necessita ser urgentemente problematizada, diz respeito à competência dos governos estaduais de definição e/ou criação de novas áreas metropolitanas. Essa responsabilidade que passou a ser do sistema estadual de planejamento precisa ser aprovada pelas assembleias legislativas, que inclusive podem propor a criação dessas áreas, via iniciativa parlamentar. Essa mudança tem trazido mais problemas que vantagens. Dessa forma, a partir da década de 1990, com o avanço do processo de urbanização da população nacional, surgem, por iniciativa dos estados, 18 novas regiões metropolitanas, conforme mostra o quadro 4.

Quadro 4: Novas Regiões Metropolitanas: população, superfície e densidade demográfica.

\begin{tabular}{|c|c|c|c|c|}
\hline $\begin{array}{c}\text { REGIÕES } \\
\text { METROPOLITANAS }\end{array}$ & DATA DE CRIAÇÃO & $\begin{array}{c}\text { POPULAÇÃO } \\
\text { TOTAL }\end{array}$ & SUPERFÍCIE $\left(\mathrm{Km}^{2}\right)$ & $\begin{array}{l}\text { DENSIDADE } \\
\left(\mathrm{habs} / \mathrm{Km}^{2}\right)\end{array}$ \\
\hline Vitória (ES) & $21 / 121995$ & 1.438 .596 & 2.286 & 629 \\
\hline $\begin{array}{c}\text { Baixada Santista } \\
\text { (SP) }\end{array}$ & $30 / 07 / 1996$ & 1.476 .820 & 2.402 & 615 \\
\hline Natal (RN) & $16 / 01 / 1997$ & 1.043 .321 & 1.907 & 547 \\
\hline Florianópolis (SC) & 06/01/1998 & 709.407 & 2.342 & 303 \\
\hline $\begin{array}{l}\text { Norte/Nordeste } \\
\text { Catarinense (SC) }\end{array}$ & 06/01/1998 & 472.568 & 2.219 & 213 \\
\hline Vale do Itajaí (SC) & 06/01/1998 & 399.901 & 1.654 & 242 \\
\hline São Luiz (MA) & $12 / 01 / 1998$ & 1.070 .688 & 1.446 & 740 \\
\hline Londrina (PR) & $17 / 06 / 1998$ & 647.854 & 3.554 & 182 \\
\hline Maringá (PR) & $17 / 07 / 1998$ & 474.202 & 2.139 & 222 \\
\hline Maceió (AL) & 19/11/1998 & 989.182 & 1.936 & 511 \\
\hline Vale do Aço (MG) & $30 / 12 / 1998$ & 399.580 & 808 & 495 \\
\hline Goiânia (GO) & $30 / 12 / 1999$ & 1.639 .516 & 3.989 & 411 \\
\hline Campinas (SP) & $19 / 06 / 2000$ & 2.338 .148 & 3.647 & 641 \\
\hline Carbonífera (SC) & 09/01/2002 & 287.272 & 1.423 & 202 \\
\hline $\begin{array}{c}\text { Foz do Rio Itajaí } \\
\text { (SC) }\end{array}$ & 09/01/2002 & 319.389 & 906 & 352 \\
\hline Tubarão (SC) & $09 / 01 / 2002$ & 117.830 & 1.780 & 407 \\
\hline Aracaju (SE) & $25 / 08 / 2003$ & 724.709 & 1.780 & 407 \\
\hline João Pessoa (PB) & $31 / 12 / 2003$ & 945.503 & 2.273 & 416 \\
\hline
\end{tabular}

Fonte: IBGE, 2000.

Assim, observamos que grande parte dessas áreas metropolitanas no Brasil não tem um perfil bem definido, nem caracterização própria e, muito menos, identidade metropolitana. Em alguns casos, municípios nitidamente rurais são introduzidos nessas regiões metropolitanas, por 
pressão política dos governantes ou dos parlamentares. Desse modo, vazios urbanos consideráveis são identificados entre municípios de RMs, ausência de problemas comuns, RMs cuja população total é inferior ao que tradicionalmente designava-se de 'cidade de médio porte', alçadas, agora, à condição de aglomerados urbanos metropolitanos, são questões que vem marcando a constituição das RMs no país.

Problemas como esses passaram a ser comumente identificáveis, desde que a responsabilidade de criação das áreas metropolitanas foi transferida para os governos estaduais e a decisão passou a ter um peso político preponderante, muitas vezes, não respaldado em critérios técnicos objetivos. A realidade metropolitana, que necessita da cooperação para se tornar "governável", torna-se um espaço de conflitos ainda maiores. A ausência de uma identidade comum, de problemas que possam ser enfrentados com medidas comuns, afasta os 'parceiros metropolitanos' anulando qualquer possibilidade de consensos em termos de resolução de problemas.

Essa situação é agravada quando o governo federal, na ausência de uma política urbana diferenciada, acena com algumas vantagens, em termos de programas e projetos para os municípios integrantes das RMs. Isso aumenta a pressão dos prefeitos sobre os parlamentares nas assembleias legislativas e a inclusão dos municípios nas RMs passa a ser um compromisso dos deputados estaduais com as suas bases político-eleitorais. As barganhas políticas prevalecem e as RMs vão se desfigurando ainda mais, tornando quase impossível a busca de saídas para os seus problemas.

\section{A REGIÃO METROPOLITANA DE NATAL-RN: UM PROCESSO AINDA EM CURSO}

No que se refere à Região Metropolitana de Natal (RMN), podemos afirmar que esta é muito recente, sendo formalmente legalizada no ano de 1997. Na atualidade é formada por 9 municípios: Natal, Parnamirim, São Gonçalo do Amarante, Macaíba, Extremoz, Ceará Mirim, Nísia Floresta, São José de Mipibú e Monte Alegre, possuindo pouco mais de 1.000 milhão de habitantes em seus respectivos $2,5 \mathrm{mil} \mathrm{km^{2 }}$ de extensão. Apresenta ainda, uma taxa de densidade demográfica (densidade média) de 344 habitantes por $\mathrm{km}^{2}$ (NÚCLEO RMNATAL/OBSERVATÓRIO DAS METRÓPOLES, 2010).

Devemos considerar ainda que, a taxa de crescimento do maior centro urbano, Natal foi da ordem de 1,81\% a.a., no período compreendido entre 1991 e 2000, enquanto que o município de Parnamirim que tem alto nível de integração como Natal cresceu em 7,9\% a.a., no mesmo período, seguido de São Gonçalo do Amarante com taxa de $4.86 \%$ a.a.

Todavia, entre os demais municípios, apenas Extremoz e Nísia Floresta apresentaram taxas superiores a 3\% a.a. Uma característica relevante sobre a capital potiguar se refere a sua população uma vez que esta se mostrou $100 \%$ urbana. Assim, sua concentração populacional cresceu de 24,28 $\mathrm{hab} / \mathrm{km}^{2}$ em 1980 para 35,26 hab/ $\mathrm{km}^{2}$ em 1991. Nesse último ano, a capital potiguar apresentava uma densidade demográfica de 3.572 hab/ $\mathrm{km}^{2}$ e em 2000, 4.192,6 hab/ $\mathrm{km}^{2}$ (NÚCLEO 
RMNATAL/OBSERVATÓRIO DAS METRÓPOLES, 2007). O quadro abaixo mostra a densidade demográfica ${ }^{5}$ da RM de Natal de 1991 a 2000.

Quadro 4: Densidade demográfica/ RM de Natal - 1991/2000

\begin{tabular}{|c|c|c|c|c|c|}
\hline Municípios & $\begin{array}{c}\text { No de Hab. } \\
\mathbf{1 9 9 1}\end{array}$ & $\begin{array}{c}\text { No de Hab. } \\
\mathbf{2 0 0 0}\end{array}$ & Área $\mathbf{( K m}^{\mathbf{2})}$ & $\begin{array}{c}\mathrm{Hab} / \mathbf{K m}^{\mathbf{2}} \\
\mathbf{( 1 9 9 1 )}\end{array}$ & $\begin{array}{c}\mathbf{H a b}_{\mathbf{K} \mathbf{K m}^{\mathbf{2}}} \\
\mathbf{( 2 0 0 0 )}\end{array}$ \\
\hline Ceará-Mirim & 52.157 & 62.424 & $\mathbf{7 2 9 , 5}$ & $\mathbf{7 1 , 5}$ & 85,6 \\
\hline Extremoz & 14.941 & 19.572 & 135,3 & 110,4 & 144,7 \\
\hline Macaíba & 43.450 & 54.883 & 492 & 88,3 & 111,5 \\
\hline Natal & 606.887 & 712.317 & 169,9 & 3572,0 & 4192,6 \\
\hline Nísia Floresta & 13.934 & 19.040 & 313,6 & 44,4 & 60,7 \\
\hline Parnamirim & 63.312 & 124.690 & 126,6 & 500,1 & 984,9 \\
\hline $\begin{array}{c}\text { São Gonçalo do } \\
\text { Amarante }\end{array}$ & 45.461 & 69.435 & 261,7 & 173,7 & 265,3 \\
\hline $\begin{array}{c}\text { São José de } \\
\text { Mipibú }\end{array}$ & 28.151 & 34.912 & 294,3 & 95,7 & 118,6 \\
\hline RM de Natal & 868.293 & $1.0972,73$ & 2522,9 & 344,2 & 434,9 \\
\hline
\end{tabular}

Fonte: Núcleo RMNATAL/Observatório das Metrópoles, 2010.

No que se refere às relações econômicas e funcionais entre Natal e sua periferia metropolitana, observamos que estas se dão sob forte influência e liderança da capital potiguar, devido à sua importância econômica e concentração de serviços públicos e privados, cuja posição se mostra de forma marcante no tecido socioeconômico da cidade. Todavia, a RM de Natal destaca-se, também, pela sua forte atividade turística. A aceleração do turismo não está devidamente refletida nas estatísticas globais do estado, particularmente no que se refere ao crescimento registrado pelo setor na década de 1990.

Hoje, o turismo é considerado o segundo maior segmento empregador do estado, só perdendo para os serviços públicos. Nesse contexto, o turismo emprega de forma direta cerca de 26.500 pessoas em todo o estado do Rio Grande do Norte. Segundo estatísticas do SEBRAE, já vivem dessa atividade, inclusive de forma indireta, cerca de, 119.524 potiguares, dos quais, 50\% destes atuam em Natal (SEBRAE, 2005). Dentre as atividades na RM de Natal destacamos: empresas dos ramos têxteis; rede hoteleira de primeira linha (hotéis de 5, 4 e 3 estrelas); indústria da construção civil e, num outro extremo, observamos uma variedade de pequenos negócios ligados ao turismo e outras atividades correlatas ou dela decorrente, garantindo ocupação a uma parcela muito significativa de mão-de-obra e que são marcados pela baixa produtividade, baixos rendimentos e pelas relações informais de trabalho.

No conjunto dos municípios que compõem a RM de Natal é possível caracterizá-las como sendo de prestadores de comércio e serviços e sedes administrativas. Em relação às atividades administrativas, além de Natal, Parnamirim, o segundo maior município da RMN, chama a atenção por apresentar um percentual que pode ser considerado alto em se tratando de atividades administrativas, fato pode ser explicado pela forte presença das forças militares da Força Aérea Brasileira (FAB) lá sediada.

Outro fato se refere aos dados de absorção da PEA (População Economicamente Ativa) referentes às atividades industriais também chamam atenção. Parte do distrito industrial de Natal se encontra

\footnotetext{
${ }^{5}$ Depois de Natal, a maior densidade demográfica das cidades que compõem a Região Metropolitana é a do município de Parnamirim, atualmente é o terceiro município em população do estado. O que tem menor densidade é o município de Nísia Floresta.
} 
em Parnamirim e nos municípios de São Gonçalo do Amarante e Extremoz. Em Macaíba e CearáMirim, essas atividades também aparecem com relativa representatividade. No setor agropecuário, o destaque são os municípios de Extremoz, Ceará-Mirim e Macaíba, como podem ser observadas no quadro 02.

\section{Quadro 5: Municípios agropecuários da RMN- PEA/2005}

\begin{tabular}{|c|c|}
\hline MUNICÍPIO & PERCENTUAL/PEA \\
\hline Extremoz & $35,9 \%$ \\
\hline Ceará - Mirim & $27,8 \%$ \\
\hline Macaíba & $24,0 \%$ \\
\hline \multicolumn{2}{|c|}{ Fonte: NESUR/IPEA, 2009. }
\end{tabular}

Todavia, devemos evidenciar que não percebemos a existência de áreas estagnadas na RM de Natal. Ao contrário, elas vão sendo incorporadas de forma muito rápida pelos processos de transbordamento e conurbação. Nesse aspecto, Natal como pólo da aglomeração urbana concentra atividades econômicas e populacionais definindo os processos de metropolização, fato que ocorre por transbordamento e/ou conurbação. Assim, a existência do núcleo metropolitano expandindo Natal - Parnamirim - São Gonçalo do Amarante vem sendo evidenciado nos anos mais recentes.

Ainda no que se refere à questão do transbordamento na RMN, observamos que este fato ocorre em virtude, principalmente desse se dá em áreas contíguas, em diferentes intensidades, motivado, primordialmente por novas relações do mercado imobiliário que se faz de forma muito forte em Natal e cidades vizinhas. Assim, um transbordamento já bem visível se dá na direção Parnamirim - Macaíba, e, ao mesmo tempo em que amplia a periferia, ratifica a situação de conurbação Natal - Parnamirim e de transbordamento de Natal - Macaíba, constituindo e fechando um primeiro arco, justificado em parte pelo crescimento da indústria tradicional reestruturada nos anos de 1990 e ai fortemente localizado pela indução governamental de um novo distrito industrial, o $\mathrm{CIA}$.

Outro fato a ser considerado é que, o turismo orienta a tendência do processo de conurbação entre o polo e as localidades costeiras urbanizadas. Entretanto, um diferencial pode ser visto no município de Nísia Floresta, uma vez que é a única sede municipal que se integra à atividade turística. $\mathrm{Na}$ verdade, as localidades costeiras, dos quatro municípios litorâneos (incluindo Natal), apresentam uma tendência de diferenciação das sedes municipais, acirrando, ainda mais o peso econômico bem como a desigualdade intrametropolitana.

Assim, isso se deve a processos tais como: a centralidade de Natal, como espaço produtivo, em relação aos municípios vizinhos, acirrando a desigualdade socioespacial; o fato de as sedes municipais também apresentarem uma relação desigual com algumas localidades costeiras, em particular no que diz respeito às dinâmicas imobiliárias, populacionais, econômicas e, sobretudo, em relação à alocação de infraestrutura, esta, por sua vez, muito concentrada em Natal bem como o fato das localidades não esboçarem um papel de sub-centralidade com relação à capital, desempenhando atividades econômicas complementares ao pólo, no que tange as atividades turísticas. Nesse sentido, Natal também estabelece uma relação desigual com essas localidades, uma vez que as mesmas não desenvolvem um terciário de maior porte. 
Desta forma, A cidade de Natal, em função de sua "vocação" turística e boa infraestrutura de comércio e serviços, atrai visitantes nacionais e estrangeiros, além de uma clientela proveniente dos mais variados lugares da hinterlândia potiguar. A RMN é frequentemente destino de uma população flutuante que busca os mais variados bens e serviços disponibilizados pela cidade (comercio atacadista e varejista, instituições bancarias e financeiras, construtoras e imobiliárias, empresas publicas e privadas, etc). Graças à sua posição de capital do Estado, Natal possui um heterogêneo mercado, materializado no espaço por intermédio de uma diversidade industrial, comercial e de serviços de interesse, também, da população local.

Entretanto, para que todo esse complexo de produção e consumo aconteça, faz-se necessário uma organização espacial que fomente a reprodução de capital, bem como garanta o acesso dos atores sociais a determinados bens ou serviços, independentemente do status social (classe social, alta, média ou baixa). Daí o papel das "vias expressas de circulação" (GOMES et al, 2000), onde são materializados os lucros e prejuízos dos atores do processo.

\section{CONSIDERAÇÕES FINAIS}

Diante de tudo isso, se torna importante lembrar que nas RMs brasileiras o conflito se sobrepõe ao consenso, fato que parece tornar ingovernáveis essas áreas. Ele tem origem em diferentes situações de incerteza, envolvendo aspectos como: o financiamento das ações de âmbito metropolitano, a desconfiança em relação a uma possível perda de autonomia dos municípios, a possibilidade do aumento do gasto público e da burocracia bem como a própria definição do âmbito metropolitano, questão muito presente no caso brasileiro na atualidade.

No caso específico do Brasil, onde a sociedade civil ainda é pouco organizada, a governança metropolitana não pode prescindir de uma coordenação de outro nível de governo, diferente dos governos municipais, potencialmente conflitantes em decorrência do atual desenho federativo brasileiro. Ultrapassar essas zonas de constrangimento é a principal tarefa da governança metropolitana, questão presente hoje, em todo o mundo. Como lembra Borja (1998)

No caso do Brasil, a dificuldade na grande maioria das áreas metropolitanas é a ausência dessa identidade metropolitana. Os movimentos organizados ainda têm como referência a participação focalizada no imediatismo do espaço da moradia. As ações coletivas e o movimento associativo de base urbana são expressões do espaço municipal, interagem com as instituições municipais de governo e não é forte o suficiente para ultrapassar, do ponto de vista político, as fronteiras das unidades territoriais formais na direção de uma atuação mais ampla.

O enfrentamento da questão da governança metropolitana e dos problemas que elas passam na atualidade, passa pela possibilidade de estabelecerem relações intergovernamentais de um novo tipo. Os municípios integrantes dessas áreas precisam ajustar os desenhos institucionais existentes na dinâmica da política descentralizada para enfrentar os problemas da metrópole, um território plurimunicipal. Nesse sentido, acreditamos que as relações intergovernamentais aparecem como um arranjo institucional de um novo tipo capaz de fazer funcionar arenas decisórias em um plano não contemplado pela organização política produzida pelo modelo federativo vigente em cada sociedade.

Sabemos das dificuldades existentes em todas as RMs do país. No entanto, acreditamos que o quadro real da problemática metropolitana no Brasil coloca a necessidade de se repensar as 
estruturas montadas até então, avaliar seus pontos de solidez e de fragilidades bem como problematizar as soluções que apostam somente no poder controlador e regulador da sociedade. Por mais que esta última solução tenha sido exitosa em algumas metrópoles no mundo, é preciso pensar a fragilidade da cultura política brasileira, das nossas instituições democráticas e dos movimentos organizados, que não incluem a participação dos setores mais vulneráveis da realidade metropolitana.

Diante disso, acreditamos que seria necessário reestruturar os atuais arranjos institucionais existentes, buscando apoio nas experiências mais exitosas realizadas no Brasil, tendo como referência o fato de que, diante de nossa realidade, faz-se necessário, ainda, a presença de uma coordenação estatal e a perspectiva de construção de uma agenda metropolitana, sob a liderança dos governos estaduais que, bem ou mal, realizam articulações institucionais e intergovernamentais com visão regional e metropolitana, utilizando-se de políticas públicas urbanas concretas para uma melhor atuação no espaço urbano, notadamente nas grandes metrópoles do país. Nesse contexto, Natal não se constitui em uma exceção. Na atualidade, muito se discute, via políticas públicas urbanas todo um contexto de problemas que vem se colocando ao longo de sua formação e que merecem desde já uma atenção maior de todos aqueles interessados nos estudos urbanos.

\section{REFERÊNCIAS}

1. GOUVÊA. Ronaldo Guimarães. A questão metropolitana no Brasil. Rio de Janeiro. FGV, 2005.

2. CINTRA, Antônio Octávio. Planejando as cidades: política ou não-política. Tradução de Haydn Coutinho Pimenta e Maristela Sette. In: CINTRA, Antônio Octávio; HADDAD, Paulo Roberto (Org.). Dilemas do planejamento urbano e regional do Brasil. Rio de Janeiro: Zahar, 1978.

3. VASCONCELOS, CRHISTIAN Lira; CÂMARA, George Luiz Rocha. Gestão metropolitana de Natal, situação atual e desafios. Uma contribuição ao debate de um novo Sistema Gestor. Natal: Secretaria de Estado do Planejamento e Finanças, 2006.

4. ALMEIDA, Maria Hermínia Tavares de. Federalismo e políticas sociais. RBCS, 1995.

5. BORJA, Jordi. La transformacion urbana de Barcelon: velocidad e globalidad. Seminário Internacional Sociedade e reforma do Estado. Ministério da Administração Federal e Reforma do Estado; São Paulo, 1998. 